\title{
Risco ambiental e gestão pública ambiental dos dez municípios gaúchos de maior potencial poluidor das indústrias
}

O trabalho analisou o risco ambiental dos dez municípios de maior potencial poluidor das indústrias no Rio Grande do Sul, no ano de 2015 , assim como a gestão pública ambiental desses municípios, no ano de 2017. Em 2015, o conjunto dos dez municípios de maior potencial poluidor das indústrias foi responsável pelo maior volume produtivo, o que contribuiu fortemente para a composição do VAB industrial do estado. Esses municípios também alocavam quase $32 \%$ dos trabalhadores industriais e concentravam cerca de 30\% da população gaúcha. Em 2017, os dez municípios contavam com boa estruturação da gestão ambiental, além da existência de Conselho Municipal de Meio Ambiente, o que sugere haver instrumentos favoráveis para controle do risco da poluição industrial nos municípios. Verificou-se a existência de legislação sobre controle ambiental em oito municípios. No entanto, existem desafios a serem enfrentados pela gestão pública ambiental em relação aos impactos ambientais, sendo a falta de saneamento, o tipo de ocorrência mais apontado.

Palavras-chave: Potencial poluidor; Risco ambiental; Gestão pública municipal; Indústrias; Rio Grande do Sul.

\section{Environmental risk and environmental management of the ten municipalities of Rio Grande do Sul with the greatest pollution potential of industries}

\begin{abstract}
The work analyzed the environmental risk of the ten municipalities with the greatest polluting potential of industries in Rio Grande do Sul, in 2015, as well as the environmental public management of these municipalities, in 2017. In 2015, the set of ten municipalities with the greatest polluting potential in the industries, it was responsible for the highest production volume, which contributed strongly to the composition of the state's industrial GVA. These municipalities also employed almost $32 \%$ of industrial workers and concentrated around 30\% of the state's population. In 2017, the ten municipalities had a good structure of environmental management, in addition to the existence of the Municipal Environment Council, which suggests that there are favorable instruments for controlling the risk of industrial pollution in the municipalities. The existence of legislation on environmental control was verified in eight municipalities. However, there are challenges to be faced by public environmental management in relation to environmental impacts, with the lack of sanitation being the most frequent type of occurrence.
\end{abstract}

Keywords: Polluting potential; Environmental risk; Municipal public management; Industries; Rio Grande do Sul.

Topic: Gestão Ambiental e da Biodiversidade

Reviewed anonymously in the process of blind peer.

Flávia Monaco Vieira (it)

Universidade La Salle, Brasil

http://lattes.cnpq.br/3124206982085534

http://orcid.org/0000-0003-0851-6506

flavia.201910304@unilasalle.edu.br

Judite Sanson de Bem (iD)

Universidade La Salle, Brasil

http://lattes.cnpq.br/1977156622994347

http://orcid.org/0000-0001-5206-5453

judite.sanson@unilassale.edu.br

Rute Henrique da Silva Ferreira

Universidade La Salle, Brasil

http://lattes.cnpq.br/6902087982100813

http://orcid.org/0000-0003-2782-626X

rute.ferreira@unilasalle.edu.br
Received: 07/01/2021

Approved: 23/03/2021
Referencing this:

VIEIRA, F. M.; BEM, J. S.; FERREIRA, R. H. S.. Risco ambiental e gestão pública ambiental dos dez municípios gaúchos de maior potencial poluidor das indústrias. Revista Brasileira de Administração Científica, v.12, n.1, p.314-327, 2021. DOI:

http://doi.org/10.6008/CBPC2179-684X.2021.001.0026 


\section{INTRODUÇÃO}

A sociedade tem testemunhado problemas ambientais, sendo que os prejuízos causados pela interferência do ser humano nos ecossistemas prejudicam tanto a flora e fauna, como a saúde humana.

Os processos industriais estão entre as atividades econômicas de maior potencial poluidor; sendo o potencial poluidor, o risco que o estabelecimento tem de causar dano ambiental, sem praticar qualquer controle ambiental. Entre os impactos ambientais causados pelas atividades industriais, pode-se citar a emissão de gases tóxicos na atmosfera, a ocorrência da perda da qualidade da água e deposição dos resíduos sólidos (MORENO, 2005; FRANCO et al., 2017).

A origem e as causas da poluição industrial são complexas de monitorar e seus efeitos podem ser cumulativos e disseminados, impactando negativamente o ar, água e solo. Não obstante, é necessário adotar medidas que minimizem a poluição industrial, tal como o monitoramento do risco ambiental, assumindo uma política preventiva (CAMPOS et al., 2016).

Os índices permitem o monitoramento da situação e as transformações ocorridas sobre o fenômeno investigado, sendo fundamentais para subsidiar a políticas públicas. Do mesmo modo, possibilitam o ajuste de metas e o redirecionamento de estratégias e ações (FRANCO et al., 2017).

Os índices ambientais, tal como o de controle da poluição decorrente das atividades produtivas, podem ser utilizados tanto para o planejamento do uso dos recursos naturais e a preservação dos ecossistemas, como para o exame dos efeitos das atividades econômicas nos territórios. Além disso, suas informações desempenham um papel fundamental no desenvolvimento vigente, podendo influenciar a opinião pública, planejadores e empresas sobre a relevância da preservação ambiental (MARTINS et al., 2006).

A qualidade ambiental de uma região pode ser afetada pelo setor industrial, especialmente para as atividades industriais com alto potencial poluidor. Indústrias que geram maiores quantidades de resíduos (sólidos, líquidos ou gasosos) durante o processo, assim como aquelas que geram resíduos mais tóxicos apresentam maior potencial poluidor (SANTOS, 2005).

A poluição é uma das eternidades negativas provenientes da atividade industrial, podendo ocorrer de forma acidental por eventos não previstos (por exemplo: vazamentos) ou pela contaminação ambiental (por exemplo: emissão de gases). Com relação à poluição, as regiões que abrigam indústrias e não possuem mecanismos de prevenção à poluição, podem apresentar um cenário particularmente crítico (JURAS, 2015).

Diante do exposto, a presente pesquisa tem por objetivo analisar o risco ambiental dos dez municípios de maior potencial poluidor das indústrias no Rio Grande do Sul, no ano de 2015, assim como avaliar a gestão pública ambiental desses municípios, no ano de 2017. Os dez municípios analisados são: Canoas, Triunfo, Caxias do Sul, Gravataí, Rio Grande, Porto Alegre, Santa Cruz do Sul, Erechim, Bento Gonçalves e São Leopoldo.

Inicialmente, o trabalho apresenta uma contextualização sobre a relação das atividades industriais com o risco ambiental e a legislação brasileira no controle dos diversos tipos de poluição. Por seguinte, é 
exposto o método de pesquisa, e a análise do risco ambiental e da gestão pública ambiental dos dez municípios considerados críticos no estado. Por fim, são realizadas as considerações finais.

Este trabalho visa contribuir para avaliação de possíveis riscos ambientais gerados pelas atividades industriais no estado, com foco nos dez municípios mais críticos, contribuindo para orientação de ações preventivas, além de servir como atenção social sobre a situação atual do potencial poluidor da região e a gestão pública ambiental destes municípios.

\section{REVISÃO TEÓRICA}

\section{Atividades Industriais e a poluição}

Apesar das atividades produtivas industriais serem importantes para a sociedade contemporânea, tanto para o crescimento da economia, como atendendo às necessidades de bens e serviços humanos, os impactos ambientais perpassam todas as fases do processo produtivo: desde a exploração de matériasprimas, transformação dessas em produtos para o consumo, utilização de recursos naturais, como a energia e água, até o descarte dos produtos pelos consumidores (MORENO, 2005).

A fim de reverter esse cenário, muitos setores têm concentrado seus esforços em busca de meios de produção mais sustentáveis, preservando os recursos naturais, materiais e energéticos. A indústria, dentro deste contexto, desempenha um papel relevante, por ser a maior consumidora de recursos, produtora de riquezas e, por muitas vezes, grande geradora de resíduos e poluição (SANTOS, 2005).

Muitas vezes se torna difícil restringir operações de empresas altamente poluentes devido a sua importância para o crescimento econômico do país. Essa situação intensifica o conflito entre proteção ambiental e danos ambientais, uma vez que essas empresas são importantes fontes de emissão de poluentes (WANG et al., 2019).

A poluição ambiental está diretamente relacionada às atividades industriais, apresentando-se como maiores fontes geradoras de resíduos perigosos e impactos ambientais. Seus efeitos podem ser percebidos principalmente quando desenvolvidos próximos a regiões densamente urbanizadas (CAMPOS et al., 2016; MORENO, 2005).

No Brasil, a Política Nacional de Meio Ambiente (PNMA) define a poluição como a degradação da qualidade ambiental resultante de atividades que: a) prejudiquem a saúde, a segurança e o bem-estar da população; b) criem condições adversas às atividades sociais e econômicas; c) afetem desfavoravelmente a biota; d) afetem as condições estéticas ou sanitárias do meio ambiente; e) lancem matérias ou energia em desacordo com os padrões ambientais estabelecidos (BRASIL, 1981).

Apesar do combate à poluição não ser algo recente, com o avanço da ciência foi possível compreendê-la de forma mais clara, assim como seus impactos na sociedade, na economia e no meio ambiente, possibilitando o desenvolvimento de tecnologias que enfrentem o problema em todas as escalas: regional e global (UNEP, 2017).

Uma das estratégias adotadas para minimizar os riscos ambientais é a prevenção à poluição e 
redução na fonte, que visa reduzir a quantidade de substâncias perigosas, poluentes ou contaminantes lançados ao meio ambiente. A prevenção à poluição parte do princípio de que os poluentes e resíduos representam ineficiências no processo produtivo e, na busca por eliminá-los, conduz a uma redução nos custos de produção, aumento na eficiência de processos e na melhoria da proteção ambiental (SANTOS, 2005). Desta forma, busca-se eliminar as causas em vez de tratar os sintomas da poluição. A imagem a seguir apresenta algumas estratégias de redução da poluição na fonte (Figura1).

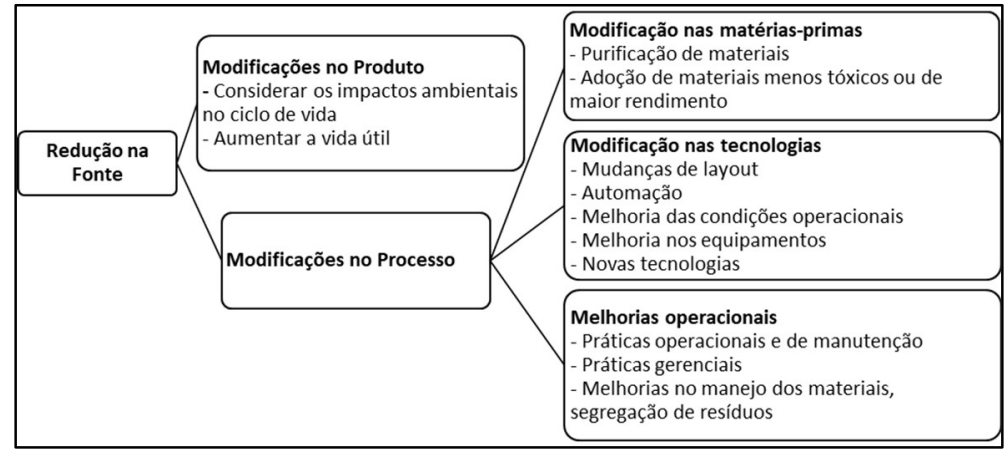

Figura 1: Redução na fonte. Fonte: Santos (2005).

Ações de controle para o problema da poluição industrial é prioritário, apesar de autores reconhecerem a complexidade do monitoramento de processos industriais, devido ao universo que compõe a origem de suas emissões e o grau dos impactos negativos no meio ambiente e a saúde humana (SANTOS, 2005; MACHADO et al., 2011).

A prevenção à poluição exige integração entre o Poder Público e empresas. Segundo Granziera (2011), "na luta contra a poluição e a degradação do meio ambiente, cabem aos Estados atuar de forma coordenada, para evitar a ocorrência de danos, assim como para racionalizar as medidas de proteção que se fizerem necessárias". Desta forma, a legislação ambiental é fundamental para regular os critérios de preservação e proteção do ambiente.

\section{Legislação brasileira no controle da poluição}

A partir da década de 1970 a preocupação com a poluição foi intensificada no Brasil, principalmente em relação à atmosférica. O poder público na busca de evitar que a qualidade do ar atingisse níveis críticos à saúde humana, adotou medidas para minimizar a poluição provocada por atividades industriais (JURAS, 2015).

O Decreto-Lei no 1.413, de 1975, foi uma das iniciativas, que passou a obrigar as indústrias a promover as medidas necessárias a prevenir ou corrigir os inconvenientes e prejuízos da poluição e da contaminação do meio ambiente. As medidas seriam definidas pelos órgãos federais competentes, no interesse do bem-estar, da saúde e da segurança das populações.

O Decreto no 76.389 , de 1975 , que dispõe sobre as medidas de prevenção e controle da poluição industrial, de que trata o Decreto-Lei no 1.413, de 1975, relacionou as áreas consideradas críticas de poluição, entre elas, constou a Região Metropolitana de Porto Alegre (Artigo 8으, VI).

O referido Decreto, em seu artigo 10, definiu poluição industrial como qualquer alteração das 
propriedades físicas, químicas ou biológicas do meio-ambiente, causadas por qualquer forma de energia ou de substância, sólida, líquida ou gasosa, ou combinação de elementos despejados pelas indústrias, em níveis capazes, direta ou indiretamente, de: I - prejudicar a saúde, a segurança e o bem-estar da população; II - criar condições adversas às atividades sociais e econômicas; III - ocasionar danos relevantes à flora, à fauna e a outros recursos naturais.

Em 1980, foi promulgada a Lei no 6.803 que estabeleceu diretrizes para o zoneamento industrial nas áreas críticas de poluição anteriormente definidas. As zonas destinadas à instalação de indústrias deferiam ser definidas em esquema de zoneamento urbano, aprovado por lei, que compatibilizasse as atividades industriais com a proteção ambiental. Foi classificada três categorias de zonas de uso: (i) estritamente industrial, (ii) predominantemente industrial, e (iii) diversificado. A Lei ainda previu licenciamento para implantação, operação e ampliação de estabelecimentos industriais (BRASIL, 1980).

Duas Resoluções do CONAMA também contribuíram para o controle da poluição do ar, sendo a Resolução CONAMA no 03, de 1990, que estabeleceu Padrões Nacionais de Qualidade do Ar e definiu padrões primários e secundários de qualidade do ar para partículas totais em suspensão, fumaça, partículas inaláveis, dióxido de enxofre, monóxido de carbono, ozônio e dióxido de nitrogênio; e a Resolução CONAMA no 08, de 1990, que estabeleceu a nível nacional, os limites máximos de emissão de poluentes no ar para processos de combustão externa em novas fontes ficas (caldeiras, geradores de vapor, fornos, estufas, etc.).

Como instrumento mais amplo, em 1981 foi instituído a Política Nacional do Meio Ambiente (PNMA), por meio da Lei $n$ ㅇ 6.938, que tratou da proteção ambiental de forma integrada, sendo previsto licenciamento para a construção, a instalação, a ampliação e o funcionamento de estabelecimentos e atividades considerados efetiva e potencialmente poluidores ou capazes de causar degradação ambiental. A PNMA criou o Conselho Nacional do Meio Ambiente (CONAMA), que teve entre suas competências, estabelecer normas, critérios e padrões relativos ao controle e à manutenção da qualidade do meio ambiente com vistas ao uso racional dos recursos ambientais.

Quanto à poluição da água, a Lei no 9.433, de 1997, instituiu a Política Nacional de Recursos Hídricos, que previu a fixação de valores para o uso dos recursos hídricos de acordo com o volume retirado e o volume e características físico-químicas, biológicas e de toxicidade do efluente lançado. A Resolução CONAMA no 357, de 2005, que substituiu a Resolução no 20, de 1986, classificou as águas de todo o Território Nacional em cinco classes: especial, 1, 2, 3 e 4, de acordo com a qualidade; para cada uma dessas classes foram estabelecidos limites ou condições para o lançamento de efluentes.

Os resíduos sólidos têm demandado maior atenção nas últimas décadas, a fim de prevenir o acúmulo e destino inadequado dos resíduos, que podem gerar e agravar a poluição do solo. Em 2010, foi aprovada a Lei no 12.305 que instituiu a Política Nacional de Resíduos Sólidos (PNRS). A PNRS dispôs sobre as diretrizes relativas à gestão integrada e ao gerenciamento de resíduos sólidos, incluídos os perigosos, às responsabilidades dos geradores e do poder público e aos instrumentos econômicos aplicáveis. Foi imposto a determinados tipos de geradores a elaboração de plano de gerenciamento de resíduos sólidos, entre os quais figuram os estabelecimentos industriais. A lei estipulou a Logística Reversa para as cadeias produtivas 
de agrotóxicos, pilhas e baterias, pneus, óleos lubrificantes, lâmpadas e produtos eletroeletrônicos. Cabe destacar que os controles dos resíduos industriais já tinham previsão legal antes da instituição da PNRS, por meio da Resolução CONAMA no 06, de 1988, substituída pela Resolução no 313, de 2002.

Quanto a poluição sonora, a Resolução CONAMA no 01 e 02, de 1990, estabeleceram normas a serem obedecidas no interesse da saúde, no tocante à emissão de ruídos em decorrência de quaisquer atividades. Outras normativas importantes para a prevenção ambiental é o Código Florestal, Lei 4.771, de 1965, substituída pela Lei no 12.651, de 2012, que previu o Plano de Suprimentos Sustentável (PSS) para indústrias que utilizam grande quantidade de matéria-prima florestal, e a Política Nacional sobre a Mudança do Clima (PNMC), instituída pela Lei no 12.187, de 2009, que previu o estabelecimento de planos setoriais de mitigação e adaptação às mudanças climáticas visando à consolidação de uma economia de baixo consumo de carbono, que contemplam os setores de geração e distribuição de energia elétrica, transporte público urbano e sistemas modais de transporte interestadual de carga e passageiros, indústria de transformação e de bens de consumo durável, indústrias químicas fina e de base, indústria de papel e celulose, mineração, indústria de construção civil, serviços de saúde e agropecuária.

\section{METODOLOGIA}

O delineamento de pesquisa adotado neste trabalho é de natureza exploratório-descritiva com abordagem predominantemente qualitativa. O objetivo é analisar o risco ambiental dos dez municípios de maior potencial poluidor das indústrias no Rio Grande do Sul, no ano de 2015 , assim como avaliar a gestão pública ambiental desses municípios, no ano de 2017.

Para caracterização do parque industrial gaúcho, foram coletados dados do IBGE e a publicação eletrônica do Atlas Socioeconômico do RS, elaborado pela da Secretaria de Planejamento, Orçamento e Gestão do Rio Grande do Sul (SEPLAG).

A fonte de dados para análise do risco ambiental do potencial poluidor foi o aplicativo InppVis, disponível na página web ${ }^{1}$, sob responsabilidade da Fundação de Economia e Estatística (FEE). O download dos dados constante no InppVis, ocorreu no dia 29 de maio de 2020, baixado com extensão xIsx.

Os principais índices para análise foram o índice de Potencial Poluidor da Indústria (Inpp-I) e Índice de Dependência do Potencial Poluidor da Indústria (Indapp-I), no período de 2002 a 2015, que corresponde aos últimos dados disponibilizados pela FEE.

Após coleta e tabulação de dados, realizou-se a análise geral do potencial poluidor industrial do Rio Grande do Sul e a análise do risco ambiental dos dez municípios com maior índice de potencial poluidor em atividades industriais. Em 2015, os munícios de Canoas; Triunfo; Caxias do Sul; Gravataí; Rio Grande; Porto Alegre; Santa Cruz do Sul; Erechim; Bento Gonçalves e São Leopoldo foram os dez municípios considerados críticos pela $\mathrm{FEE}$, por serem os municípios com maiores volumes de produção potencialmente poluidora no território gaúcho.

${ }^{1}$ http://visualiza.dee.planejamento.rs.gov.br/inpp/ 
Cabe destacar, que os índices do potencial poluidor desenvolvidos pela FEE não tratam da medição da carga poluidora em si, mas da adoção da classificação de potencial poluidor das atividades econômicas utilizadas pela Fepam, no enquadramento dos empreendimentos para fins de licenciamento ambiental, qualificando, quanto ao potencial de risco ambiental, as 281 classes da indústria de transformação e extrativa que constam da Classificação Nacional das Atividades Econômicas (CNAE) da Fundação Instituto Brasileiro de Geografia e Estatística (IBGE).

Martins et al. (2006) entendem que o índice pode apresentar algumas limitações em termos de seu alcance, pois ele relata exclusivamente o risco representado pelo potencial de poluição, sem considerar o estágio da tecnologia de controle do empreendimento industrial, nem as características ambientais da região. Para complementar a análise dos dez municípios gaúchos considerados críticos quando ao potencial poluidor, buscou-se avaliar a gestão pública ambiental. Para a realização da avaliação foram utilizadas as informações coletadas da pesquisa de Informações Básicas Municipais - Munic, do Instituto Brasileiro de Geografia e Estatística (IBGE), edição 2017. O download da base de dados, constante no website do IBGE, ocorreu no dia 30 de maio de 2020, baixado com extensão xls.

\section{RESULTADOS E DISCUSSÃO}

\section{Caracterização do Parque Industrial do Estado do Rio Grande do Sul}

O Estado do Rio Grande do Sul, está localizado na Região Sul do Brasil, sendo composto por 497 municípios que ocupam uma área de $281.730,2 \mathrm{~km}^{2}$, incluindo as áreas referentes a Laguna dos Patos e Lagoa Mirim (IBGE - Resolução no 05 de 10/10/2002).

Em 2018 havia 45.072 empresas industriais no Rio Grande do Sul, correspondendo ao terceiro estado $(9,7 \%)$ com maior número de estabelecimentos no setor industrial brasileiro. Empregava 762.045 trabalhadores, $26,3 \%$ da força de trabalho do estado.

A Indústria de Transformação possuía 35.672 estabelecimentos e 632.056 empregados, a Indústria Extrativa Mineral contava com 644 estabelecimentos e 5.522 empregados; e a Construção Civil com 16.640 estabelecimentos e 104.112 empregados. A Figura 2 apresenta a distribuição espacial dos estabelecimentos da indústria de transformação e extrativa mineral, no ano de 2018.

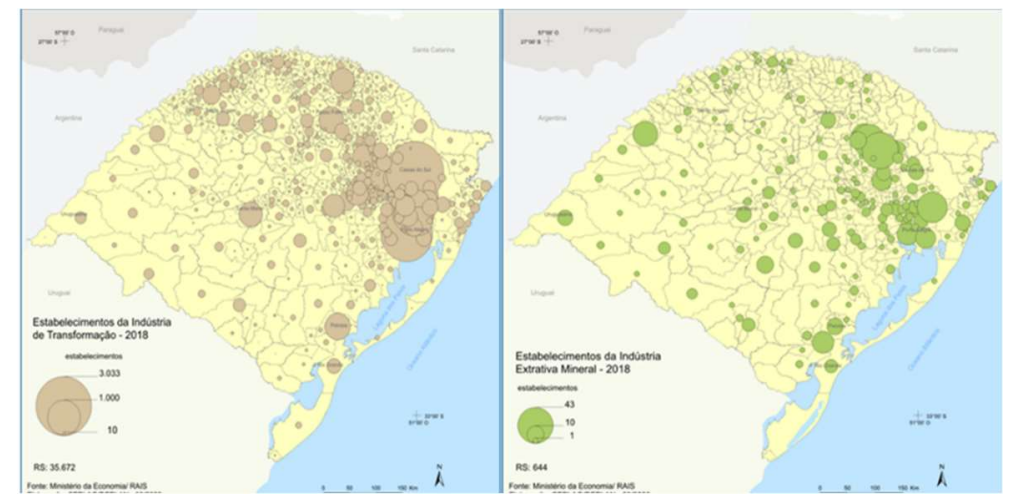

Figura 2: Estabelecimentos Indústria de transformação e Extrativa Mineral 2018.

O Rio Grande do Sul apresenta uma indústria diversificada que se desenvolveu a partir das 
agroindústrias e de outros segmentos ligados ao setor primário. Em 2017, o Estado apresentou o quinto maior Valor Adicionado Bruto $\left(\mathrm{VAB}^{2}\right)$ da indústria brasileira, contribuindo com aproximadamente 82 bilhões (6,86\%), frente os $R \$ 1,2$ trilhões gerados no Brasil.

Na matriz do VAB do Estado do Rio Grande do Sul, o setor industrial respondeu por 22,4\% do total, em 2017, sendo que 16,0\% correspondem a Indústria de Transformação, enquanto a Indústria Extrativista possui uma participação pouco expressiva, com apenas $0,1 \%$ do VAB total do estado.

Na tabela 1 está representada a distribuição das indústrias de transformação e do pessoal ocupado no Estado do Rio Grande do Sul, em 2017, ordenado de forma decrescente por número de unidades locais.

Tabela 1: Distribuição industrial e do pessoal ocupado no Rio Grande do Sul - 2017.

\begin{tabular}{|l|l|l|l|}
\hline Divisão industrial e Descrição & $\begin{array}{l}\text { Unidades } \\
\text { Locais (i) }\end{array}$ & $\begin{array}{l}\text { Pessoal } \\
\text { ocupado (ii) }\end{array}$ & $\begin{array}{l}\text { Densidade de pessoal } \\
\text { ocupado (ii/i) }\end{array}$ \\
\hline 10 Produtos alimentícios & 2677 & 130213 & 49 \\
\hline 25 Produtos de metal, exceto máquinas e equipamentos & 2389 & 50233 & 21 \\
\hline 15 Preparação e fabricação de artefatos de couro & 2027 & 104657 & 52 \\
\hline 31 Móveis & 1515 & 39083 & 26 \\
\hline 28 Máquinas e equipamentos & 1348 & 53495 & 40 \\
\hline 14 Artigos do vestuário e acessórios & 1324 & 22376 & 17 \\
\hline 23 Produtos de minerais não-metálicos & 1306 & 21382 & 16 \\
\hline 16 Produtos de madeira & 1133 & 14117 & 12 \\
\hline 22 Produtos de borracha e de material plástico & 955 & 33510 & 35 \\
\hline 32 Fabricação de produtos diversos & 664 & 17290 & 26 \\
\hline 33 Manutenção e instalação de máquinas e equipamentos & 588 & 12616 & 21 \\
\hline 20 Produtos químicos & 519 & 17908 & 35 \\
\hline 18 Impressão e reprodução de gravações & 471 & 6350 & 13 \\
\hline 29 Veículos automotores, reboques e carrocerias & 422 & 37090 & 88 \\
\hline 27 Máquinas, aparelhos e materiais elétricos & 303 & 11254 & 37 \\
\hline 13 Produtos têxteis & 300 & 8697 & 29 \\
\hline 17 Celulose, papel e produtos de papel & 292 & 11621 & 40 \\
\hline 11 Bebidas & 251 & 10922 & 44 \\
\hline 26 Equipamentos de informática, eletrônicos e ópticos & 218 & 11064 & 51 \\
\hline 24 Metalurgia & 201 & 8353 & 42 \\
\hline 12 Produtos do fumo & 52 & 5978 & 115 \\
\hline 30 Outros equipamentos de transporte, exceto veículos automotores & 48 & 3006 & 63 \\
\hline 21 Produtos farmoquímicos e farmacêuticos & 38 & 1839 & 48 \\
\hline 19 Coque, produtos derivados do petróleo e biocombustíveis & 12 & 1282 & 107 \\
\hline TOTAL & 19053 & 634336 & 33 \\
\hline Fonte: & & \\
\hline
\end{tabular}

Fonte: IBGE (2017). Pesquisa Industrial Anual 2017 - Empresa.

Está presente dentro do estado, todos os setores econômicos da cadeia produtiva industrial brasileira, o que demonstra uma estrutura manufatureira bastante diversificada, apesar de haver uma concentração em um número reduzido de divisões.

A maioria dos estabelecimentos pertencem a 5 divisões industriais, sendo elas: Fabricação de Produtos Alimentícios (14,05\%); Fabricação de Produtos de metal, exceto máquinas e equipamentos (12,54\%); Preparação de couro e fabricação de artefatos de couro (10,64\%); Fabricação de Móveis (7,95\%) e Fabricação de Máquinas e equipamentos (7,08\%). As demais 19 divisões industriais correspondem a 47,75\% das unidades locais.

Com relação ao emprego, as divisões industriais com maior número de pessoal ocupado são:

\footnotetext{
${ }^{2}$ Valor Adicionado Bruto (VAB) é o valor que cada setor da economia (agropecuária, indústria e serviços) acresce ao valor final de tudo que foi produzido em uma região. (FEE, 2020).
} 
Fabricação de Produtos Alimentícios (20,53\%); Preparação de couro e fabricação de artefatos de couro (16,50\%); Fabricação de Máquinas e equipamentos (8,43\%); Fabricação de Produtos de metal, exceto máquinas e equipamentos (7,92\%) e Fabricação de Móveis (6,16\%). Juntas elas empregam 377681 trabalhados, ou seja, $59,54 \%$ do total de empregos proporcionados pela indústria de transformação no estado.

No entanto, as divisões industriais que apresentam a maior densidade ocupacional, são: Fabricação de produtos do fumo; Fabricação de coque, de produtos derivados do petróleo e de biocombustíveis e Fabricação de veículos automotores, reboques e carrocerias. Proporcionalmente ao número de unidades locais, estas divisões são as que mais empregam no estado, indicando indústrias de maior porte. Em contrapartida, as divisões industriais: Fabricação de produtos de maneira; Impressão e reprodução de gravações; Fabricação de produtos de minerais não-metálicos e Confecção de artigos do vestuário e acessórios, representam indústrias menores.

\section{Análise do potencial poluidor}

Para avaliar os riscos ambientais do setor industrial parte-se da verificação da situação do Estado do Rio Grande do Sul (RS) como um todo, observando o Índice de Potencial Poluidor da Indústria (Innp-I) (Figura 2) e o Índice de Dependência do Potencial Poluidor da Indústria (Indapp-I) (Figura 3), do ano de 2002 até 2015.

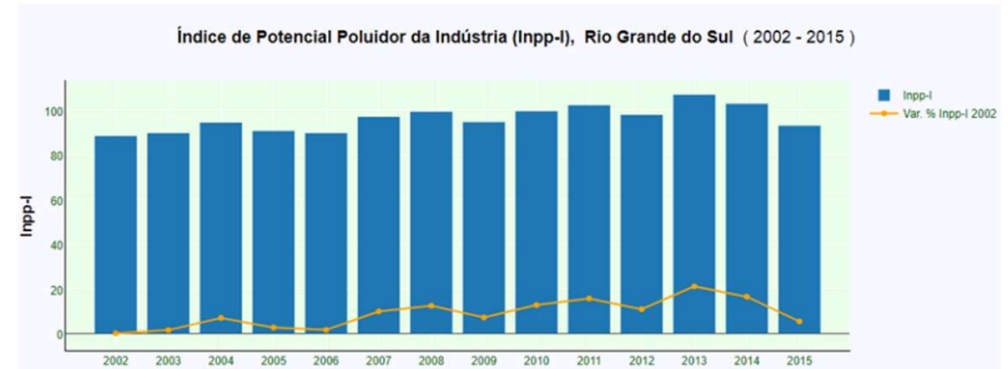

Figura 2: Índice de Potencial Poluidor da Indústria no RS. Fonte: FEE (2020)

Houve uma variação de 5,36\% do Inpp-I do RS entre os anos de 2002 e 2015, tendo atingido o maior valor no ano de 2013 (índice geral de 106.799), que correspondia a uma variação de 21,02\% sobre o valor de 2002. Nos anos de 2014 e 2015 observa-se um decréscimo no índice, sendo de 102.718 e 92.978 , respectivamente.

Referente ao Índice de Dependência do Potencial Poluidor da Indústria (Indapp-I) observa-se que a dependência permaneceu no mesmo patamar nos últimos três anos, valor de 0,855 . A variação do índice de 2002 a 2015 foi de 3,66\%, sendo o ápice no ano de 2010, com valor de 0,878 .

Apesar da taxa de crescimento da indústria ter diminuído nos anos de 2014 e 2015 (FEE, 2017) o que influenciou o decréscimo do Inpp-I desses anos, devido à redução do volume de produção potencialmente poluidora, o Indapp-I não variou, demonstrando que de forma geral a dependência pelas indústrias de alto potencial poluidor permaneceu igual no território. Assim, pode-se considerar que a queda do Inpp-I não reduziu o risco ambiental das atividades industriais. 


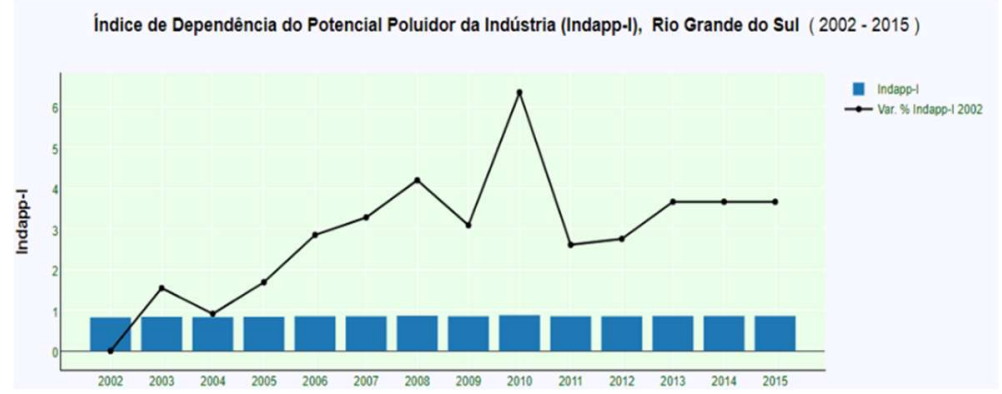

Figura 3: Evolução do Indapp-I no RS. Fonte: FEE (2020).

O Índice de Potencial Poluidor considera a classificação das atividades industriais de transformação e extrativa pelo seu potencial poluidor (baixo, médio e alto) em cada município com base nas saídas fiscais nos setores de interesse. O Nível baixo de concentração do Indapp-I vai de 0 a 0,399; o nível médio vai de 0,4 a 0,6999 e o nível alto vai de 0,7 a 1. A tabela 2 apresenta a quantidade de municípios em cada nível de concentração do Indapp-I (alto, médio, baixo), do ano de 2002 a 2015.

Tabela 2: Quantidade de municípios por nível de concentração de Indapp-I

\begin{tabular}{l|l|l|l} 
Ano & Alto & Médio & Baixo \\
\hline 2002 & 225 & 251 & 21 \\
\hline 2003 & 223 & 246 & 28 \\
\hline 2004 & 230 & 238 & 29 \\
\hline 2005 & 218 & 254 & 25 \\
\hline 2006 & 225 & 246 & 26 \\
\hline 2007 & 222 & 240 & 35 \\
\hline 2008 & 223 & 238 & 36 \\
\hline 2009 & 228 & 239 & 30 \\
\hline 2010 & 235 & 234 & 28 \\
\hline 2012 & 247 & 219 & 31 \\
\hline 2013 & 251 & 220 & 26 \\
\hline 2014 & 242 & 230 & 25 \\
\hline 2015 & 242 & 230 & 25 \\
\hline
\end{tabular}

Fonte: FEE (2020).

Conforme demonstrado na tabela 1, em 2002, 225 municípios (45,27\%) dependiam de indústrias de alto potencial poluidor; 251 municípios (50,50\%) dependiam de indústrias com médio potencial poluidor e 21 (4,23\%) concentravam indústrias com baixo potencial poluidor. Em 2015 houve uma alteração e uma piora: 242 municípios (48,69\%) dependiam de indústrias de alto potencial poluidor, 230 (46,28\%) dependia de indústrias de meio potencial poluidor e 25 (5,03\%) de baixo risco.

No decorrer dos anos, observou-se um aumento de municípios dependentes de indústrias de alto potencial poluidor: 17 municípios que dependiam de indústrias de médio potencial poluidor passaram a depender de indústrias de alto potencial. Enquanto 4 municípios que dependiam de indústrias de médio potencial poluidor passaram a depender de indústrias de baixo potencial.

Partindo para análise dos municípios, em termos do volume da produção industrial e do risco ambiental, observa-se que 10 municípios, no ano de 2015 , concentraram 59,5\% do volume de produção potencialmente poluidora. A tabela 3 apresenta os dez municípios com maior índice de potencial poluidor em atividades industriais (Inpp-I), no ano de 2015. 
Tabela 3: Ranking dos dez municípios com maior Inpp-I no ano de 2015.

\begin{tabular}{l|l|l|l|l|l|l|l|l|l|l|l|l} 
Município & Inpp-I & $\begin{array}{l}\text { Part. } \\
\text { Inpp- } \\
\text { I RS }\end{array}$ & $\begin{array}{l}\text { Indapp- } \\
\text { I }\end{array}$ & $\begin{array}{l}\text { Nível } \\
\text { Indapp- } \\
\text { In }\end{array}$ & $\begin{array}{l}\text { PIB } \\
\text { (R\$ 1000) }\end{array}$ & $\begin{array}{l}\text { VAB Ind. } \\
\text { (R\$ } \\
\mathbf{1 0 0 0}\end{array}$ & $\begin{array}{l}\text { VAB total } \\
\text { (R\$ 1000) }\end{array}$ & $\begin{array}{l}\text { Part. } \\
\text { VAB } \\
\text { Ind. } \\
\text { (\%) }\end{array}$ & $\begin{array}{l}\text { Part. } \\
\text { VAB } \\
\text { RS } \\
\text { (\%) }\end{array}$ & Estab & Empr & Popul \\
\hline Canoas & $\mathbf{1 7 , 1 1 2}$ & 19,39 & 0,984 & Alto & 16244021 & 5487395 & 14122827 & 38,85 & 7,09 & 727 & 14184 & 350824 \\
\hline Triunfo & $\mathbf{9 , 3 2 7}$ & 10,57 & 0,998 & Alto & 7478984 & 4734634 & 6435788 & 73,57 & 6,11 & 70 & 3245 & 26263 \\
\hline Caxias do Sul & $\mathbf{6 , 8 1 1}$ & 7,72 & 0,899 & Alto & 20637192 & 5624756 & 17477011 & 32,18 & 7,26 & 3262 & 65891 & 475906 \\
\hline Gravataí & $\mathbf{5 , 2 3 8}$ & 5,94 & 0,96 & Alto & 9730604 & 3532773 & 7748877 & 45,59 & 4,56 & 709 & 20415 & 273611 \\
\hline Rio Grande & $\mathbf{3 , 7 8 9}$ & 4,29 & 0,991 & Alto & 7274580 & 1770461 & 6310061 & 28,06 & 2,29 & 198 & 11960 & 213166 \\
\hline Porto Alegre & $\mathbf{3 , 1 9 6}$ & 3,62 & 0,791 & Alto & 68117224 & 6669847 & 58241423 & 11,45 & 8,61 & 2348 & 32975 & 1475717 \\
\hline Santa Cruz do Sul & $\mathbf{1 , 9 8 5}$ & 2,25 & 0,527 & Médio & 7764848 & 1942346 & 5785621 & 33,57 & 2,51 & 427 & 10003 & 128437 \\
\hline Erechim & $\mathbf{1 , 7 1 5}$ & 1,94 & 0,711 & Alto & 4262167 & 1365433 & 3742718 & 36,48 & 1,76 & 546 & 12556 & 103074 \\
\hline Bento Gonçalves & $\mathbf{1 , 6 8 8}$ & 1,91 & 0,881 & Alto & 5253990 & 1620637 & 4497006 & 36,04 & 2,09 & 936 & 17670 & 117227 \\
\hline São Leopoldo & $\mathbf{1 , 6 7 2}$ & 1,89 & 0,801 & Alto & 6932552 & 1625166 & 5944300 & 27,34 & 2,01 & 735 & 17342 & 226546 \\
\hline
\end{tabular}

Fonte: FEE (2020).

Os municípios de maior risco, considerados críticos no Estado do Rio Grande do Sul, no ano de 2015 eram: Canoas, Triunfo, Caxias do Sul, Gravataí, Rio Grande, Porto Alegre, Santa Cruz do Sul, Erechim, Bento Gonçalves e São Leopoldo (Tabela 2).

A maioria dos municípios críticos apresentava um percentual superior a 30\%, referente à participação da indústria na sua economia (Tabela 2). Triunfo foi o município que teve a maior participação da indústria no seu VAB total $(73,57 \%)$, seguido por Gravataí $(45,59 \%)$ e Canoas $(38,85 \%)$.

Do VAB industrial do estado, aproximadamente $45 \%$ está concentrado nos municípios críticos de potencial poluidor industrial (Tabela 2), com destaque para o município de Porto Alegre com participação de 8,61\% (VAB da indústria de 6,6 bilhões), seguido por Caxias do Sul com participação de 7,3\% (5,6 bilhões); Canoas 7,1\% (5,4 bilhões); Triunfo 6,1\% (4,7 bilhões) e Gravataí 4,6\% (3,5 bilhões). Somando os percentuais desses quatros municípios verifica-se que eles foram responsáveis por um terço do VAB da indústria do Rio Grande do Sul (33,64\%), demonstrando sua importância para a economia gaúcha.

Entre os municípios considerados críticos, verifica-se que Caxias do Sul e Porto Alegre eram os municípios com maior número de estabelecimentos industriais (3.262 e 2.348, respectivamente), bem como possuíam a maior quantidade de trabalhadores alocados no setor industrial, sendo 65.891 empregados em Caxias do Sul e 32.975 em Porto Alegre (Tabela 2).

Ao avaliar a densidade de pessoal ocupado (número de trabalhadores dividido pelo número de estabelecimentos), verifica-se que as empresas de maior porte estavam localizadas em Rio Grande $(60,40)$ e Triunfo $(46,35)$ e os estabelecimentos de menor porte estavam localizadas em Porto Alegre $(14,04)$, Bento Gonçalves $(18,87)$ e Canoas $(19,51)$. Os demais municípios ficaram com média de 23,8 trabalhadores por unidade.

Quanto a dimensão populacional dos municípios, verifica-se que Porto Alegre possuía mais de 1 milhão de habitantes, enquanto Canoas, Caxias do Sul, Gravataí, Rio Grande, Santa Cruz do Sul, Erechim, Bento Gonçalves e São Leopoldo se situavam na faixa de tamanho de população que vai de 100.001 a 500.000 habitantes. Triunfo tem a menor densidade populacional, com 26.263 habitantes. O conjunto desses municípios abriga um terço da população total do Estado.

Analisado o risco do potencial poluidor dos 10 municípios considerado críticos, buscou-se a avaliação 
da gestão ambiental municipal. Para tanto, as informações foram coletadas da pesquisa do IBGE (2018), que revelara o perfil dos municípios brasileiros no ano de 2017. Selecionaram-se quatro temas sobre a gestão ambiental, com finalidade de apresentar a situação em termos de ações públicas ambientais, sendo eles: estruturação da gestão municipal do meio ambiente; existência e caráter do Conselho Municipal de Defesa do Meio Ambiente (COMDEMAS); legislação ambiental sobre a área/zona de proteção ou controle ambiental e ocorrência de algum impacto ambiental (Tabela 4).

Tabela 4: Gestão ambiental nos dez municípios de maior potencial poluidor industrial.

\begin{tabular}{|c|c|c|c|c|c|c|}
\hline Município & Estruturação & $\begin{array}{l}\text { COM } \\
\text { DEMA }\end{array}$ & Caráter do Conselho & $\begin{array}{l}\text { Legisl. } \\
\text { Controle } \\
\text { Amb. }\end{array}$ & $\begin{array}{l}\text { Ocorrência de } \\
\text { Impacto } \\
\text { ambiental }\end{array}$ & Tipo de Ocorrência \\
\hline Canoas & $\begin{array}{l}\text { Secretaria } \\
\text { exclusiva }\end{array}$ & Sim & $\begin{array}{l}\text { Consultivo; } \\
\text { Deliberativo; } \\
\text { Fiscalizador }\end{array}$ & Sim & Sim & $\begin{array}{l}\text { Condições climáticas; } \\
\text { Moradias em risco } \\
\text { ambiental; } \\
\text { Falta de saneamento }\end{array}$ \\
\hline Triunfo & $\begin{array}{l}\text { Secretaria } \\
\text { exclusiva }\end{array}$ & Sim & $\begin{array}{l}\text { Consultivo e } \\
\text { Deliberativo }\end{array}$ & Não & Sim & $\begin{array}{l}\text { Desmatamento; } \\
\text { Degradação áreas } \\
\text { protegidas; Falta de } \\
\text { saneamento }\end{array}$ \\
\hline $\begin{array}{l}\text { Caxias do } \\
\text { Sul }\end{array}$ & $\begin{array}{l}\text { Secretaria } \\
\text { exclusiva }\end{array}$ & Sim & $\begin{array}{l}\text { Consultivo; } \\
\text { Deliberativo }\end{array}$ & Não & Sim & $\begin{array}{l}\text { Poluição d'água; } \\
\text { Desmatamento; } \\
\text { Falta de saneamento }\end{array}$ \\
\hline Gravataí & $\begin{array}{l}\text { Órgão da } \\
\text { administração } \\
\text { indireta }\end{array}$ & Sim & Deliberativo & Sim & Sim & $\begin{array}{l}\text { Desmatamento; } \\
\text { Moradia em risco } \\
\text { ambiental; Falta de } \\
\text { saneamento }\end{array}$ \\
\hline Rio Grande & $\begin{array}{l}\text { Secretaria } \\
\text { exclusiva }\end{array}$ & Sim & $\begin{array}{l}\text { Deliberativo, } \\
\text { Normativo; } \\
\text { Fiscalizador }\end{array}$ & Sim & Sim & $\begin{array}{l}\text { Poluição do ar; } \\
\text { Poluição d'água; } \\
\text { Falta de saneamento }\end{array}$ \\
\hline $\begin{array}{l}\text { Porto } \\
\text { Alegre }\end{array}$ & $\begin{array}{l}\text { Secretaria } \\
\text { exclusiva }\end{array}$ & Sim & $\begin{array}{l}\text { Consultivo; } \\
\text { Deliberativo }\end{array}$ & Sim & Não & \\
\hline $\begin{array}{l}\text { Santa Cruz } \\
\text { do Sul }\end{array}$ & $\begin{array}{l}\text { Secretaria } \\
\text { exclusiva }\end{array}$ & Sim & $\begin{array}{l}\text { Consultivo; } \\
\text { Deliberativo; } \\
\text { Normativo }\end{array}$ & Sim & Sim & $\begin{array}{l}\text { Condições climáticas; } \\
\text { Moradias em risco } \\
\text { ambiental; Falta de } \\
\text { saneamento }\end{array}$ \\
\hline Erechim & $\begin{array}{l}\text { Secretaria } \\
\text { exclusiva }\end{array}$ & Sim & $\begin{array}{l}\text { Consultivo; } \\
\text { Deliberativo; } \\
\text { Normativo }\end{array}$ & Sim & Sim & $\begin{array}{l}\text { Poluição d'água; } \\
\text { Desmatamento; } \\
\text { Falta de saneamento }\end{array}$ \\
\hline $\begin{array}{l}\text { Bento } \\
\text { Gonçalves }\end{array}$ & $\begin{array}{l}\text { Secretaria } \\
\text { exclusiva }\end{array}$ & Sim & $\begin{array}{l}\text { Consultivo; } \\
\text { Deliberativo; } \\
\text { Normativo; } \\
\text { Fiscalizador }\end{array}$ & Sim & Sim & $\begin{array}{l}\text { Poluição do ar; } \\
\text { Diminuição da } \\
\text { biodiversidade; } \\
\text { Moradia em risco } \\
\text { ambiental }\end{array}$ \\
\hline $\begin{array}{l}\text { São } \\
\text { Leopoldo }\end{array}$ & $\begin{array}{l}\text { Secretaria } \\
\text { exclusiva }\end{array}$ & Sim & $\begin{array}{l}\text { Consultivo; } \\
\text { Deliberativo; } \\
\text { Normativo; } \\
\text { Fiscalizador }\end{array}$ & Sim & Sim & $\begin{array}{l}\text { Poluição do ar; } \\
\text { Poluição d'água; } \\
\text { Assoreamento d'água }\end{array}$ \\
\hline
\end{tabular}

Fonte: IBGE (2017). Pesquisa de Informações Básicas Municipais.

Os resultados obtidos demonstram que em 2017 todos os municípios analisados possuíam algum tipo de estrutura ambiental, sendo que nove municípios contavam com uma secretaria municipal exclusiva, considerada a melhor forma de estruturação ambiental conforme o IBGE (2018). O município de Gravataí foi o único onde a estrutura ambiental correspondia a um órgão da administração indireta (Tabela 4).

Todos os dez municípios dispunham de um Conselho Municipal de Defesa do Meio Ambiente, apesar de possuírem caráter diferente entre si (Tabela 3). Observa-se que havia predominância pelo caráter deliberativo (100\%), seguido daqueles com caráter consultivo (80\%) e caráter deliberativo (50\%). Somente 
quatro Conselhos possuíam o caráter fiscalizador.

Quanto à existência de legislação municipal sobre área e/ou zona de proteção ou controle ambiental, constatou-se que oito municípios confirmaram sua existência, enquanto os municípios de Caxias do Sul e Triunfo não possuíam essa legislação. Referente aos impactos ambientais, Porto Alegre foi o único município que não apontou nenhuma ocorrência (Tabela 4).

O maior número de ocorrências de impacto ambiental foi a falta de saneamento ( $77,78 \%)$, seguido por poluição de algum corpo d'água (55,56\%); existência de moradia em situação de risco ambiental (44.44\%) e desmatamento (44,44\%). Alguns municípios apontaram também a ocorrências de condições climáticas extremas; poluição do ar; assoreamento de algum corpo d'água; degradação de áreas legalmente protegidas e diminuição da biodiversidade - fauna e flora.

\section{CONCLUSÕES}

Os impactos ambientais oriundos da poluição industrial são capazes de danificar ecossistemas e prejudicar a saúde humana, sendo assim, torna-se necessário o controle da poluição das atividades econômicas. Um dos meios de monitoramento do ambiente são os índices ambientais, que além de permitir avaliar a situação atual e a evolução no decorrer do tempo, contribui para o planejamento urbano e conscientização ambiental. Além disso, a gestão pública ambiental pode ser um instrumento de controle da poluição industrial. Desta forma, essa pesquisa buscou analisar o risco ambiental e a gestão pública ambiental dos dez municípios de maior potencial poluidor das indústrias no Rio Grande do Sul.

Os dados coletados demonstram um aumento de risco ambiental no estado do Rio Grande do Sul, entre os anos de 2002 e 2015, tanto no potencial poluidor como na dependência de atividades poluidoras.

No ano de 2015 o ranking dos dez municípios gaúchos de maior potencial poluidor das indústrias foi composto, de forma descente, pelos seguintes munícipios: Canoas, Triunfo, Caxias do Sul, Gravataí, Rio Grande, Porto Alegre, Santa Cruz do Sul, Erechim, Bento Gonçalves e São Leopoldo. Coube a esse conjunto de municípios o maior volume produtivo, o que contribuiu fortemente para a composição do VAB industrial do estado. Esses municípios também alocavam quase 32\% de todos os empregados da atividade industrial e concentravam em torno de $30 \%$ da população gaúcha.

Em 2017, os dez municípios contavam com boa estruturação da gestão ambiental, além da existência de Conselho Municipal de Meio Ambiente, o que sugere haver instrumentos favoráveis no controle do risco da poluição industrial do município.

Apesar de todos os Conselhos Municipais de Meio Ambiente terem o caráter deliberativo e a maioria ter o caráter consultivo, poucos possuíam a atribuição de fiscalizar. Observou-se ainda, que os Conselhos dos quatro primeiros municípios considerados críticos (Canoas; Triunfo; Caxias do Sul e Gravataí) juntamente com o Conselho de Porto Alegre não possui a atribuição normativa, caráter encontrado nos demais cinco municípios.

Verificou-se a existência de legislação sobre área e/ou zona de proteção ou controle ambiental em oito municípios. No entanto, ainda há desafios a serem enfrentados pela gestão pública ambiental em relação 
aos impactos ambientais, sendo a falta de saneamento, o tipo de ocorrência mais apontado.

\section{REFERÊNCIAS}

BRASIL. Decreto Lei n.1.413, de 14 de agosto de 1975. Dispõe sobre o controle da poluição do meio ambiente provocada por atividades industriais. Brasília: DOU, 1975.

BRASIL. Decreto Lei n.76.389 de 03 de outubro de 1975. Dispõe sobre as medidas de prevenção e controle da poluição industrial, de que trata o decreto lei 1413, de 14 de agosto de 1975, e das outras providencias. Brasília: DOU 1975.

BRASIL. Lei n.6.803, de 2 de julho de 1980. Dispõe sobre as diretrizes básicas para o zoneamento industrial nas áreas críticas de poluição, e dá outras providências. Brasília: DOU, 1980.

BRASIL. Lei n.6.938, de 31 de agosto de 1981. Dispõe sobre a Política Nacional do Meio Ambiente, seus fins e mecanismos de formulação e aplicação, e dá outras providências. Brasília: DOU, 1981.

BRASIL. Lei n.9.433/97 de 09 de janeiro de 1997. Institui a Política Nacional de Recursos Hídricos, cria o Sistema Nacional de Gerenciamento de Recursos Hídricos, regulamenta o inciso XIX do art. 21 da Constituição Federal, e altera o art. 10 da Lei n.8.001, de 13 de março de 1990, que modificou a Lei no 7.990, de 28 de dezembro de 1989. Brasília: DOU, 1997.

BRASIL. Lei n.12.187, de 29 de dezembro de 2009. Instituiu a Política Nacional sobre Mudança do Clima - PNMC e dá outras providências. Brasília: DOU, 2009.

BRASIL. Lei n.12.305 de 02 de agosto de 2010. Institui a Política Nacional de Resíduos Sólidos; altera a Lei no 9.605, de 12 de fevereiro de 1998; e dá outras providências. Brasília: DOU, 2010.

CAMPOS, I. A. Z.; MARQUES, C.. Direito ao meio ambiente e o necessário controle da poluição atmosférica: a inovação trazida pelo estado do Espírito Santo. Revista Jurídica, v.2, n.43, p.407-428, 2016. DOI: https://doi.org/10.22456/2317$\underline{8558.65851}$

FEE. Fundação de Economia e Estatística. O InppVis. Porto Alegre: FEE, 2020.

FEE. Fundação de Economia e Estatística. RS em números: 2017. Porto Alegre: FEE, 2017.
FRANCO, F. A.; SCHNORR, G. P.; MARQUES, R.. Índice do potencial poluidor das indústrias no estado de Mato Grasso: uma análise da variação entre os anos de 2000, 2005 e 2010. Caminhos de Geografia, v.18, n.63, p.202-222, 2017. DOI: https://doi.org/10.14393/RCG186309

GRANZIERA, M. L. M.. Direito ambiental. São Paulo: Atlas. 2011.

IBGE. Instituto Brasileiro de Geografia e Estatística. Perfil dos municípios brasileiros: 2017. Rio de Janeiro: IBGE, 2018.

IBGE. Instituto Brasileiro de Geografia e Estatística. Pesquisa de Informações Básicas Municipais: Munic. IBGE, 2017.

JURAS, I. A. G. M.. Os impactos da indústria no meio ambiente. In: GANEN, R. S.. Políticas setoriais e meio ambiente. Brasília: Câmara dos Deputados, 2015. p.47- 83.

MACHADO, H. H. S.; OLIVEIRA, J. C. D.; MENEGUETTI, K. S.. Potencial poluidor de atividades industriais: estudo de casoMaringá-PR. In: EPCC-ENCONTRO INTERNACIONAL DE PRODUÇÃO CIENTÍFICA-CESUMAR, 7. Anais. CESUMAR, 2011.

MARTINS, C. H. B.; OLIVEIRA, N.. Desenvolvimento e meio ambiente: potencial poluidor das atividades industriais e gestão ambiental municipal no Rio Grande do Sul. Indicadores Econômicos FEE, v.34, n.2, p.71-80, 2006.

MORENO, R. A. M.. Estimativa de Potencial Poluidor nas Indústrias: o caso do Estado do Rio de Janeiro. Dissertação (Mestrado em Ciências e Planejamento Energético) Universidade Federal do Rio de Janeiro, Rio de Janeiro, 2005.

SANTOS, C.. Prevenção à poluição industrial: identificação de oportunidades, análise dos benefícios e barreiras. Tese (Doutorado em Ciências da Engenharia Ambiental) Universidade de São Paulo, São Paulo, 2005.

UNEP. United Nations Environment Assembly of the United Nations Environment Programme. Towards a pollution-free planet. UNEP, 2017.

WANG, W.; ZHAO, X.; CHEN, F.-W.; WU, C.-H.; TSAI, S.-B.; WANG, J.. The Effect of Corporate Social Responsibility and Public Attention on Innovation Performance: Evidence from High-polluting Industries. International Journal of Environmental Research and Public Health, v.16, n.20, 2019.

A CBPC - Companhia Brasileira de Produção Científica (CNPJ: 11.221.422/0001-03) detém os direitos materiais desta publicação. Os direitos referem-se à publicação do trabalho em qualquer parte do mundo, incluindo os direitos às renovações, expansões e disseminações da contribuição, bem como outros direitos subsidiários. Todos os trabalhos publicados eletronicamente poderão posteriormente ser publicados em coletâneas impressas sob coordenação da Sustenere Publishing, da Companhia Brasileira de Produção Científica e seus parceiros autorizados. Os (as) autores (as) preservam os direitos autorais, mas não têm permissão para a publicação da contribuição em outro meio, impresso ou digital, em português ou em tradução. 